\title{
Risk Evaluation for Antipsychotic Agents Used in Elderly Inpatients (REPAIR)
}

\author{
Flora Yu, Reza Rafizadeh, Vincent H Mabasa, and Nirmal Kang
}

\begin{abstract}
Background: Antipsychotics have been approved for the treatment of certain psychiatric illnesses. However, these medications are also frequently used off label, and recent studies have suggested a concerning potential increase in the risk of death when used by elderly patients with dementia. Most of the available literature focusing on off-label use of antipsychotics comes from long-term care facilities; there is a lack of quantitative data for elderly patients in the acute care setting. This study was designed to examine this scenario and to identify potential quality improvement opportunities to minimize harm.

Objectives: The primary objectives were to determine the prevalence of hospital-initiated off-label use of antipsychotics for elderly inpatients and to determine the plan for these drugs upon discharge. The secondary objectives included identifying the most common diagnosis and the most common agent used.
\end{abstract}

Methods: A retrospective cohort study was performed with a convenience sample. Patients included in the analysis were elderly adults ( $\geq 65$ years) who had been admitted to either of 2 medical units at a community hospital between September 1 and November 8, 2014. Descriptive statistics were used to examine prevalence patterns for the off-label use of antipsychotics.

Results: A total of 250 patients were included in the analysis. Forty-five patients $(18 \%$, 95\% confidence interval [CI] 13.7\%-23.2\%) received a hospital-initiated antipsychotic for off-label use during the admission. For 27 (60\%, 95\% CI 45.5\%-73.0\%) of these 45 patients, the off-label therapy was discontinued upon discharge or death, and for $13(29 \%, 95 \%$ CI $17.7 \%-43.4 \%$ ), the agent was continued upon discharge without a plan in place. The most frequent diagnosis was delirium, and the agent most frequently used was haloperidol.

Conclusions: Off-label antipsychotic therapy was initiated for almost 1 in every 5 elderly patients receiving care in 2 medical units at a community hospital. These findings suggest a need to monitor and reassess the off-label use of these agents, especially at the time of discharge. Keywords: antipsychotic, off-label use, elderly patients, atypical antipsychotic, conventional antipsychotic

Can J Hosp Pharm. 2018;71(6):370-5

\section{RÉSUMÉ}

Contexte : Les antipsychotiques ont été approuvés pour le traitement de certains troubles psychiatriques. Or, ces médicaments sont aussi fréquemment utilisés en dérogation des directives de l'étiquette et des études récentes ont supposé une potentielle augmentation préoccupante du risque de décès lorsqu'ils sont employés pour traiter des patients âgés atteints de démence. La majeure partie de la littérature portant sur l'emploi non conforme d'antipsychotiques provient de centres d'hébergement et de soins de longue durée. Or, on constate un manque de données quantitatives sur les patients âgés dans les milieux de soins de courte durée. La présente étude a été conçue pour examiner ce scénario et découvrir de potentielles occasions d'amélioration de la qualité en vue de réduire au minimum les risques de préjudice.

Objectifs : Les objectifs principaux étaient de déterminer la prévalence de l'emploi non conforme d'antipsychotiques amorcé à l'hôpital chez les patients aînés et de déterminer le plan relatif à la prescription de ces médicaments au moment du congé. Les objectifs secondaires incluaient de déterminer quels étaient le diagnostic le plus fréquent et le médicament le plus utilisé.

Méthodes : Une étude de cohorte rétrospective a été menée à l'aide d'un échantillon de commodité. Les patients retenus pour l'analyse étaient des personnes âgées (de 65 ans et plus) ayant été admises à l'une des deux unités médicales dans un hôpital communautaire entre le $1^{\text {er }}$ septembre et le 8 novembre 2014. Des statistiques descriptives ont été employées pour analyser les modèles de prévalence en ce qui concerne l'emploi non conforme d'antipsychotiques.

Résultats : Au total, 250 patients ont été retenus pour l'analyse. Pendant l'hospitalisation, un antipsychotique a été amorcé hors conformité chez 45 patients (18\%, intervalle de confiance [IC] de $95 \%$ de $13,7 \%$ à $23,2 \%)$. Pour $27(60 \%$, IC de $95 \%$ de $45,5 \%$ à $73,0 \%)$ de ces 45 patients, le traitement non conforme a été arrêté au moment du congé et, pour 13 autres (29\%, IC de $95 \%$ de 17,7\%-43,4\%), le traitement a été poursuivi au congé sans mise en place d'un plan. Le diagnostic motivant le plus souvent l'emploi non conforme de ces médicaments était le délire et le médicament le plus employé était l'halopéridol.

Conclusions : Le traitement non conforme par antipsychotique a été amorcé pendant le séjour à l'hôpital pour près d'un patient âgé sur cinq qui recevait des soins dans l'une des deux unités médicales d'un hôpital communautaire. Ces résultats laissent croire qu'une surveillance de l'emploi non conforme de ces médicaments et qu'une réévaluation d'un tel traitement sont nécessaires, particulièrement au moment du congé.

Mots clés : antipsychotique, emploi non conforme, patients âgés, antipsychotique atypique, antipsychotique classique 


\section{INTRODUCTION}

ntipsychotic agents, both conventional and atypical, are indicated for the treatment of certain psychiatric illnesses, such as schizophrenia, bipolar disorder, and refractory depression. ${ }^{1,2}$ Conventional agents have been available since the mid-1900s, but use of the "newer" atypical agents has been on the rise, because these agents are described as having similar benefits with fewer adverse effects. ${ }^{3}$

Antipsychotic agents are frequently used off label, especially in elderly patients, for various conditions, including behavioural and neuropsychiatric symptoms in dementia, delirium, anxiety, obsessive-compulsive disorder, eating disorders, depression, and substance abuse. ${ }^{1,4}$ For treatment of behavioural and neuropsychiatric symptoms in dementia (e.g., agitation, aggression, delusions, hallucinations, repetitive vocalization, and wandering), nonpharmacological measures are generally recommended as first-line management. ${ }^{5}$ However, in cases of severe aggression or psychosis, antipsychotics are often administered, given the ease of use in clinical practice, as well as the absence of other effective agents. ${ }^{3,6}$

In 2008, the US Food and Drug Administration issued a warning ${ }^{7}$ about the use of all antipsychotics, both conventional and atypical agents, based on 2 cohort studies that showed an increased risk of death among elderly patients being treated for dementia-related psychosis. ${ }^{6,8}$ In one of these cohort studies, Gill and others ${ }^{6}$ found that use of a new atypical antipsychotic was associated with an increased risk of death at 30 days, relative to non-use, with adjusted hazard ratios (HRs) of 1.31 (95\% confidence interval [CI] 1.02-1.70) for the community-dwelling cohort and 1.55 (95\% CI 1.15-2.07) for the long-term care cohort. When conventional and atypical antipsychotics were compared, there was higher risk of death at 30 days in the conventional antipsychotic group, with adjusted HRs of 1.55 (95\% CI 1.19-2.02) for the community-dwelling cohort and 1.26 (95\% CI 1.04-1.53) for the long-term care cohort. ${ }^{6}$ In addition, Schneider and others ${ }^{9}$ suggested an increase in the risk of death with use of atypical antipsychotics, relative to placebo, for brief periods of use (less than 8 to 12 weeks). In terms of adverse effects, use of antipsychotics in elderly patients has also been described as contributing to the risk of stroke and falls. ${ }^{10,11}$ In terms of efficacy in the treatment of behavioural and neuropsychiatric symptoms of dementia, there is no clear evidence of benefit for the use of antipsychotics. ${ }^{1,12,13}$ Given the mounting evidence that suggests risk of harm and the controversial evidence of benefit, the American Geriatrics Society has recommended the avoidance of all antipsychotics for "behavioral problems of dementia unless non-pharmacological methods have failed and the patient is a threat to self or others" ${ }^{14}$ Health Canada ${ }^{15}$ and the Canadian Geriatrics Society ${ }^{16}$ have issued similar advisories and recommendations.

Despite the aforementioned health concerns, it appears that off-label use of antipsychotics is still quite common. For example, in a cross-sectional analysis published in 2008, Kamble and others ${ }^{17}$ reported the prevalence of and factors associated with antipsychotic drug use among elderly nursing home residents in the United States. The authors found that nearly 1 in 4 elderly nursing home residents received antipsychotic agents for off-label diagnoses, with the majority of use occurring in patients with dementia (70\%), depression (41\%), and anxiety (18\%). This study was restricted to nursing home residents. The focus of the study reported here was to investigate the prevalence of off-label use of antipsychotics for elderly patients admitted to hospital and to identify any potential quality improvement opportunities to minimize harm.

\section{METHODS}

This retrospective cohort study involved patients at a 300bed community hospital. The study received ethics approval from the local research ethics board.

The primary objectives of the study were to determine the extent of hospital-initiated off-label use of antipsychotics and to determine whether a postdischarge treatment plan was in place at the time of discharge. Hospital-initiated use of an antipsychotic was defined as use of an antipsychotic for a patient who had not been taking antipsychotic medications just before admission (i.e., all agents of this class were newly initiated in hospital). Off-label use was defined as use of a drug for an indication not reported in the Health Canada drug product monograph for that particular agent. Secondary objectives were to determine the percentage of patients with dementia for whom off-label antipsychotic use was initiated in hospital, and to characterize the most common diagnosis and the most common agent used for these off-label purposes.

Patients eligible for inclusion were elderly adults (at least 65 years of age) admitted to either of 2 designated medical units for elderly patients at a community hospital between September 1 and November 8, 2014. Eligible patients were identified from a patient list generated by the hospital's health and business analytics department according to the study's inclusion criteria. In cases of readmission of the same patient, the first admission was included in the analysis; subsequent admissions were excluded.

All data were collected from electronic and scanned health records (i.e., admission, consultation, progress, nursing, and discharge notes) within the hospital's database. The following data were collected for each patient: demographic and clinical characteristics (age, sex, and relevant comorbidities); use of antipsychotics just before admission, during admission, and upon discharge (drug name, type of antipsychotic, indication, and dosing regimen); and plan at discharge for hospital-initiated antipsychotics with off-label use (discontinuation by prescriber, discontinuation because of patient death, continuation with no plan, or continuation with a plan). Having a plan was defined as any mention in the discharge summary of follow-up for the hospital-initiated antipsychotic with off-label use. 
A convenience sample size of 250 patients was chosen by consensus among the investigators. All data were analyzed with descriptive statistics.

\section{RESULTS}

A total of 260 patient encounters from the 2 medical units met the inclusion criteria. Of these, 10 were readmissions; for these patients, only the initial admission was included in the analysis, and subsequent admissions were excluded, leaving the desired sample size of 250 . Overall, 164 (66\%) of the 250 patients were women, and patient age ranged from 65 to 98 years (median 83.5 years, interquartile range 70.5-96.5 years) (Table 1). Sixteen (6\%) of the patients had been receiving an antipsychotic for off-label use before admission.

Off-label use of an antipsychotic was initiated during the hospital admission for 45 (18\%, 95\% CI 13.7\%-23.2\%) of the patients. For 27 (60\%, 95\% CI 45.5\%-73.0\%) of these patients, off-label therapy was discontinued upon discharge or death. Upon discharge, 18 patients (40\%, 95\% CI 27.0\%-54.6\%) had these agents continued (Figure 1). Notably, for 13 patients (29\%, 95\% CI 17.7\%-43.4\%), the drug was continued at discharge with no reported plan in place for further assessment or discontinuation in the community.

In terms of the secondary outcomes (Table 2), we found that hospital-initiated off-label use of an antipsychotic was ordered for $26(32 \%)$ of the 82 patients with a history of dementia. For all patients with off-label use of antipsychotics, the diagnoses were recorded, and these are reported in Table 2. The most common antipsychotics used were haloperidol and loxapine (Table 2).

Sixteen $(6 \%)$ of patients in this study had off-label use of an antipsychotic before admission. We found that these patients were

\section{Table 1. Baseline Characteristics}

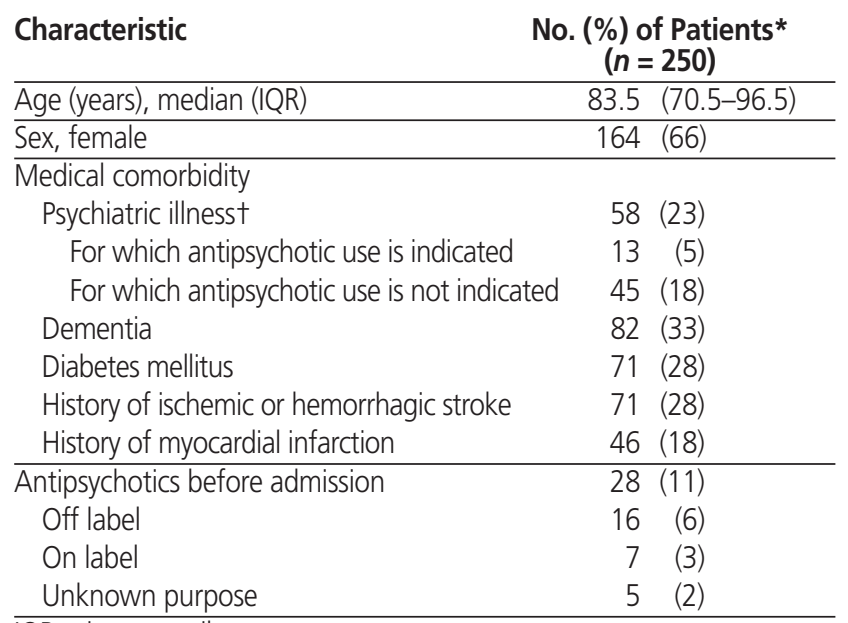

$\mathrm{IQR}=$ interquartile range.

*Except where indicated otherwise.

tIncludes mood disorders (e.g., depression, bipolar disorder), schizophrenia, anxiety disorders, eating disorders, addictive behaviours, and personality disorders.

still receiving antipsychotic therapy upon discharge. Compared with the time of admission, 9 of these 16 patients had the same antipsychotic regimen and 7 had a change in regimen (a dosing change or addition of another agent) at the time of discharge. Interestingly, none of these patients were free of off-label antipsychotic use at discharge.

\section{DISCUSSION}

The objective of this study was to characterize hospitalinitiated off-label use of antipsychotics in the elderly population.

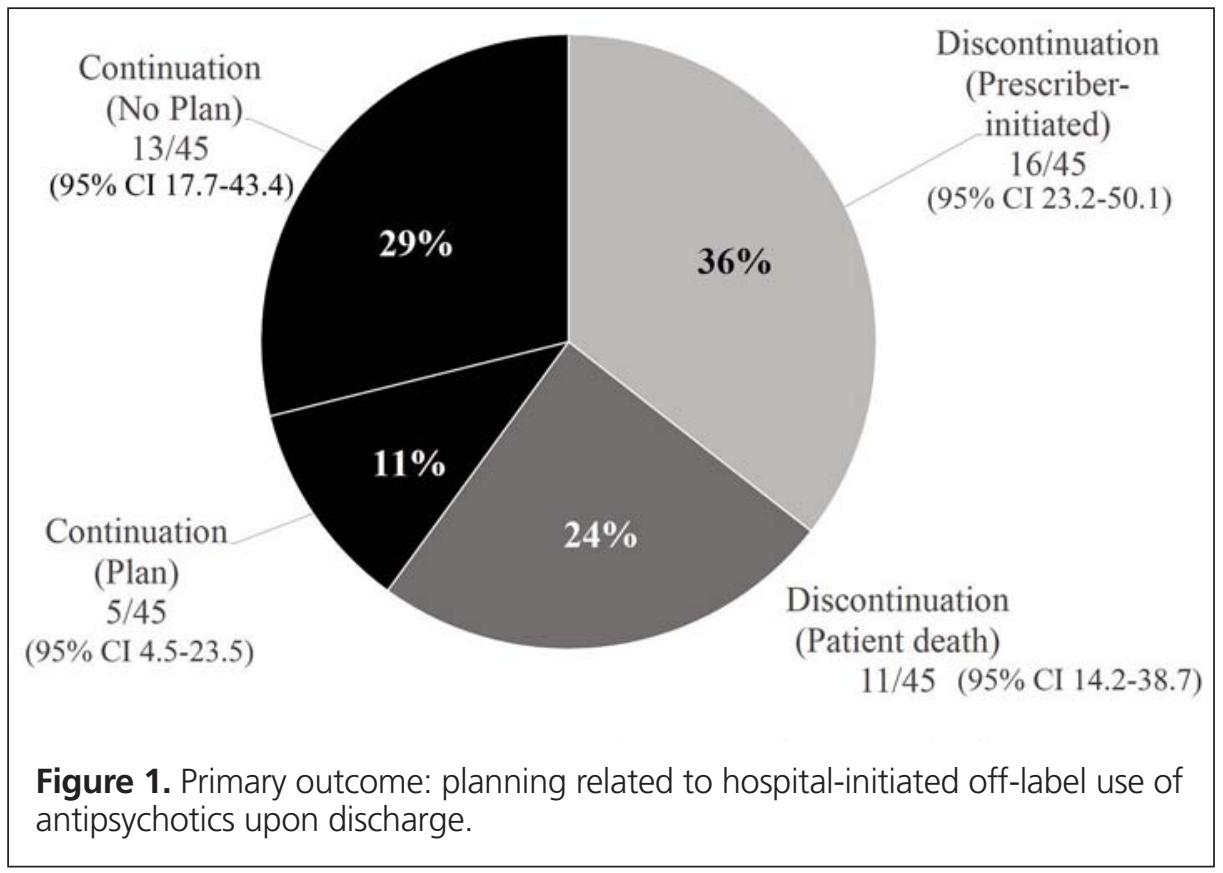




\section{Table 2. Secondary Outcomes}

\begin{tabular}{|c|c|}
\hline Outcome & No. $(\%)$ of Patients \\
\hline $\begin{array}{l}\text { Hospital-initiated off-label antipsychotic use } \\
\text { for patient with dementia }\end{array}$ & $26 / 82(32)$ \\
\hline $\begin{array}{l}\text { Regimen for hospital-initiated off-label } \\
\text { antipsychotic use }\end{array}$ & $n=45$ patients \\
\hline Regular basis only & $2(4)$ \\
\hline As-needed basis only (prn) & $23(51)$ \\
\hline Both regular and as needed & $20(44)$ \\
\hline \multicolumn{2}{|l|}{$\begin{array}{l}\text { Diagnosis relevant to hospital-initiated off-label } \\
\text { antipsychotic uset }\end{array}$} \\
\hline Delirium & 34 \\
\hline Agitation & 29 \\
\hline Nausea & 6 \\
\hline $\begin{array}{l}\text { Behavioural and neuropsychiatric symptoms } \\
\text { in dementia }\end{array}$ & 5 \\
\hline Insomnia & 3 \\
\hline End of life & 1 \\
\hline Anxiety & 1 \\
\hline \multicolumn{2}{|l|}{ Antipsychotic ordered $t$} \\
\hline Haloperidol & 27 \\
\hline Loxapine & 25 \\
\hline Quetiapine & 18 \\
\hline Olanzapine & 1 \\
\hline Risperidone & 1 \\
\hline
\end{tabular}

*Except where indicated otherwise.

†These data relate to a total of 45 patients with hospital-initiated off-label use of an antipsychotic. Data are presented as numbers of patients, without percentages, and the sum of data values is greater than 45 because some patients had more than one diagnosis or more than one antipsychotic ordered.

In this study, $18 \%$ of patients were newly initiated on an antipsychotic (off-label use) at some point during their hospital admission. Importantly, none of these patients had been taking an antipsychotic before admission; however, an additional $6 \%$ of patients were already receiving off-label antipsychotic therapy before admission, which means a higher overall number of patients receiving this type of therapy while in hospital.

During the writing of this article, 2 additional studies were published addressing the off-label use of antipsychotics in the hospital setting. ${ }^{18,19}$ In a retrospective cohort study of 17775 patients (age 18 years or older), Herzig and others ${ }^{18}$ examined the use of antipsychotics for delirium in a hospital setting. These authors found that $9 \%$ of patients were taking an antipsychotic while in hospital, with such therapy being newly initiated for 5\%; these rates are much lower than observed in our study. One factor may have been a difference in age between the patient populations: about half $(50.4 \%)$ of their patients were between the ages of 18 and 64 years, whereas the patients in our study were 65 years or older. In fact, Herzig and others ${ }^{18}$ reported age 75 years or older as a characteristic associated with a higher rate of antipsychotic initiation (relative risk 1.4, 95\% CI 1.2-1.7). This could explain the lower rate in their study compared with ours. The other study, a research letter, examined the use of antipsychotics in hospitalized elderly patients (age 65 years or older). ${ }^{19}$ The authors of that study similarly found that $9 \%$ of patients were receiving an antipsychotic while in hospital; however, they did not specify whether the drug therapy was newly initiated in patients who had not been taking antipsychotic medications before admission. ${ }^{19}$

In our study, even though most hospital-initiated agents were discontinued upon discharge, either at the prescriber's direction or because of patient death, we were mainly interested in the 18 patients whose antipsychotic medications were continued after discharge (representing $40 \%$ of the 45 patients with antipsychotics newly initiated during the hospital stay). Interestingly, Herzig and others $^{18}$ reported a much lower rate $(26 \%)$ for continuation of antipsychotics at discharge; however, they excluded patients who died during hospitalization or who left against medical advice. For an interesting comparison, if we were to exclude the 11 patients in our study who died, the percentage would increase to 53\% (18 of 34 patients) whose hospital-initiated agents were continued on discharge. Once again, this finding may have been influenced by the age of our patient population. Loh and others ${ }^{19}$ reported a more comparable rate (48\%) for elderly patients whose antipsychotics were continued at discharge.

Of concern in our study, hospital-initiated off-label use of antipsychotics was continued at discharge without any plan for $29 \%$ of patients. Among the $11 \%$ of patients for whom there was a plan, common discharge plans included follow-up with a family physician, mental health clinic, or geriatric psychiatrist (e.g., monitor QTc, taper or discontinue the antipsychotic). Kamble and others ${ }^{17}$ found that $24.82 \%$ of elderly nursing home residents received an antipsychotic at some point over the course of a year. In clinical practice, a hospital stay preceding transfer to a nursing home facility is common, especially for elderly patients. Although our study was not designed to specifically characterize a direct association between hospital-initiated off-label use of antipsychotics and an influx of these agents into nursing homes, such an association remains a possibility. Medications are easy to initiate at times of immediate need, but opportunities to re-evaluate and deprescribe are often missed. ${ }^{20}$ A future study focusing on the downstream effects of hospital-initiated off-label use of antipsychotics on patients transferred back to the community would be of great importance.

In this study, the most common diagnoses for hospitalinitiated off-label use of antipsychotics were delirium and agitation. Herzig and others ${ }^{18}$ and Loh and others ${ }^{19}$ also reported delirium as the most common indication. As defined by the American Psychiatric Association's Diagnostic and Statistical Manual of Mental Disorders, ${ }^{21}$ delirium is a disturbance in attention and awareness, which develops over a short period of time, represents a change from baseline, and fluctuates during the course of the day. In the context of this diagnosis, off-label use of antipsychotics may be helpful in situations where a patient is a threat to self or others, ${ }^{14}$ but these agents need to be regularly 
assessed for appropriateness and effectiveness. The Confusion Assessment Method (CAM) is a simple tool that is frequently used by clinicians to assess delirium (sensitivity $94 \%-100 \%$, specificity 90\%-95\%). ${ }^{22}$ At our community hospital, CAM scores are recorded daily in the nursing notes; however, given the retrospective design of our study, ambiguity arose regarding the interpretation of documented CAM scores.

The results presented here suggest a preference for conventional agents at our site, although the literature suggests popularity of atypical agents, given similar efficacy and fewer adverse effects. Herzig and others ${ }^{18}$ and Loh and others ${ }^{19}$ both reported more frequent use of atypical antipsychotics. Our community hospital has a preprinted order for geriatric delirium. For severe agitation or psychosis, quetiapine $6.25-12.5 \mathrm{mg} \mathrm{PO}$ q2h prn (maximum $50 \mathrm{mg}$ in $24 \mathrm{~h}$ ) and/or loxapine $2.5 \mathrm{mg}$ PO q $4 \mathrm{~h}$ prn (maximum $10 \mathrm{mg}$ in $24 \mathrm{~h}$ ) is recommended. For severe agitation when an oral agent cannot be used, haloperidol $0.25 \mathrm{mg}$ IM or SC q1h prn (maximum $1.5 \mathrm{mg}$ in $24 \mathrm{~h}$ ) is recommended. For all of these agents, the preprinted order specifies an automatic stop date of 3 days, which encourages reassessment. In the study reported here, the agents most commonly used were haloperidol, loxapine, and quetiapine (in descending order), which is consistent with the agents recommended in the preprinted order. However, most of the orders analyzed in the study were free-text handwritten orders; preprinted orders were not used. We did not specifically look at the appropriateness of dosing regimens; nonetheless, better education about and awareness among staff physicians regarding the use of preprinted orders would ensure greater dosing consistency and would encourage more frequent reassessment of the need for ongoing off-label use of antipsychotics.

This study had several limitations that could affect interpretation of the results. Given the retrospective design, data were collected by reviewing scanned charts in the electronic database, but these records may have been incomplete and inconsistent. More specifically, the study relied heavily on dictated discharge summaries to identify the plan for hospital-initiated off-label use of antipsychotics upon discharge. In addition, data on antipsychotics were obtained from electronic medication records, which indicate what has been prescribed but not necessarily actual administration of the drug. For our study, documentation of actual administration was unnecessary, because we did not assess hard end points associated with harm (e.g., death, stroke). If a future study assessing such end points were to be conducted, use of medication administration records would be preferable. Furthermore, the study results were drawn from a small convenience sample at a single centre, and therefore may not be generalizable to other sites.

\section{CONCLUSION}

In this study, about 1 in every 5 patients was newly initiated on an antipsychotic for off-label use during hospital admission, with the most common diagnosis being delirium. Nearly a third (29\%) of patients were receiving a hospital-initiated agent at discharge with no documented plan for reassessment or discontinuation in the community. These findings were presented to hospitalists and nurses at the study site. These discussions led to improved awareness about this issue and development of an action plan to assist in improving current practices.

\section{References}

1. Maher AR, Maglione M, Bagley S, Suttorp M, Hu JH, Ewing B, et al. Efficacy and comparative effectiveness of atypical antipsychotic medications for off-label uses in adults: a systematic review and meta-analysis. JAMA. 2011;306(12):1359-69.

2. Christian R, Saavedra L, Gaynes BN, Sheitman B, Wines RCM, Jonas DE, et al. Future research needs for first- and second-generation antipsychotics for children and young adults. Future Research Needs Paper No. 13. (Prepared by the RTI-UNC Evidence-based Practice Center under Contract No. 290200710056 I.) Rockville (MD): Agency for Healthcare Research and Quality; 2012 [cited 2018 Dec 2]. Available from: https://effective healthcare.ahrq.gov/sites/default/files/pdf/antipsychotics-children-future_ research.pdf

3. Sink KM, Holden KF, Yaffe K. Pharmacological treatment of neuropsychiatric symptoms of dementia: a review of the evidence. JAMA. 2005; 293(5):596-608.

4. Savva GM, Zaccai J, Matthews FE, Davidson JE, McKeith I, Brayne C. Prevalence, correlates and course of behavioural and psychological symptoms of dementia in the population. Br J Psychiatry. 2009;194(3):212-9.

5. Ayalon L, Gum AM, Feliciano L, Areán PA. Effectiveness of nonpharmacological interventions for the management of neuropsychiatric symptoms in patients with dementia: a systematic review. Arch Intern Med. 2006; 166(20):2182-8.

6. Gill SS, Bronskill SE, Normand SLT, Anderson GM, Sykora K, Lam K, et al. Antipsychotic drug use and mortality in older adults with dementia. Ann Intern Med. 2007;146(11):775-86.

7. Information for healthcare professionals: conventional antipsychotics. Silver Spring (MD): US Food and Drug Administration; 2008 [updated 2013 Aug 15; cited 2018 Dec 02]. Available from: http://wayback.archive-it.org/7993/ 20171115034437/https://www.fda.gov/Drugs/DrugSafety/PostmarketDrug SafetyInformationforPatientsandProviders/ucm124830.htm

8. Schneeweiss S, Setoguchi S, Brookhart A, Dormuth C, Wang PS. Risk of death associated with use of conventional versus atypical antipsychotic drugs among elderly patients. CMAJ. 2007;176(5):627-32.

9. Schneider LS, Dagerman KS, Insel P. Risk of death with atypical antipsychotic drug treatment for dementia: meta-analysis of randomized placebocontrolled trials. JAMA. 2005;294(15):1934-43.

10. Gill SS, Rochon PA, Herrmann N, Lee PE, Sykora K, Gunraj N, et al. Atypical antipsychotic drugs and risk of ischaemic stroke: population based retrospective cohort study. BMJ. 2005;330(7489): 445 .

11. Bloch F, Thibaud M, Dugué B, Brèque C, Rigaud AS, Kemoun G. Psychotropic drugs and falls in the elderly people: updated literature review and meta-analysis. J Aging Health. 2011;23(2):329-46.

12. Franco KN, Messinger-Rapport B. Pharmacological treatment of neuropsychiatric symptoms of dementia: a review of the evidence. J Am Med Dir Assoc. 2006;7(3):201-2.

13. Lee PE, Gill SS, Freedman M, Bronskill SE, Hillmer MP, Rochon PA. Atypical antipsychotic drugs in the treatment of behavioural and psychological symptoms of dementia: systematic review. BMJ. 2004;329(7457):75.

14. American Geriatrics Society 2012 Beers Criteria Update Expert Panel. American Geriatrics Society updated Beers Criteria for potentially inappropriate medication use in older adults. J Am Geriatr Soc. 2012;60(4):616-31.

15. Atypical antipsychotic drugs and dementia - advisories, warnings and recalls for health professionals. Ottawa (ON): Health Canada; 2005 [cited 2018 Dec 2]. Available from: http://www.healthycanadians.gc.ca/recall-alertrappel-avis/hc-sc/2005/14307a-eng.php 
16. Canadian Geriatrics Society. Five things physicians and patients should question. Toronto (ON): Choosing Wisely Canada; 2014 [updated 2017 Jun; cited 2018 Jun 24]. Available from: https://choosingwiselycanada.org/ geriatrics/

17. Kamble P, Chen H, Sherer J, Aparasu RR. Antipsychotic drug use among elderly nursing home residents in the United States. Am J Geriatr Pharmacother. 2008;6(4):187-97.

18. Herzig SJ, Rotherberg MB, Guess JR, Stevens JP, Marhsall J, Gurwitz JH, et al. Antipsychotic use in hospitalized adults: rates, indications, and predictors. J Am Geriatr Soc. 2016;64(2):299-305.

19. Loh KP, Ramdass S, Garb JL, Brennan MJ, Lindenauer PK, Lagu T. From hospital to community: use of antipsychotics in hospitalized elders. J Hosp Med. 2014;9(12):802-4.

20. Frank C, Weir E. Deprescribing for older patients. CMAJ. 2014;186 (18):1369-76.

21. American Psychiatric Association. Diagnostic and statistical manual of mental disorders. 5th ed. Washington (DC): APA Press; 2013.

22. Inouye SK, van Dyck CH, Alessi CA, Balkin S, Siegal AP, Horwitz RI. Clarifying confusion: the confusion assessment method. A new method for detection of delirium. Ann Intern Med. 1990;113(12):941-8.
Flora Yu, BSc(Pharm), ACPR, is a Clinical Pharmacist with Vancouver General Hospital, Vancouver, British Columbia.

Reza Rafizadeh, BSC(Pharm), ACPR, BCPP, is a Clinical Pharmacist in Mental Health and Substance Use with the Burnaby Centre for Mental Health \& Addiction, Burnaby, British Columbia.

Vincent H Mabasa, BSC(Pharm), ACPR, PharmD, is Clinical Coordinator with the Burnaby Hospital, Burnaby, British Columbia

Nirmal Kang, MBBS, FRCPC, is a Psychiatrist with the Burnaby Hospital, Burnaby, British Columbia

Competing interests: None declared.

Address correspondence to:

Flora Yu

Pharmacy Department

Vancouver General Hospital

899 West 12th Avenue

Vancouver BC V5Z $1 \mathrm{M} 9$

e-mail: florawei.yu@vch.ca

Funding: None received. 